\title{
What Happened to the Transatlantic Capital Market Relations?
}

\section{Enzo Weber*}

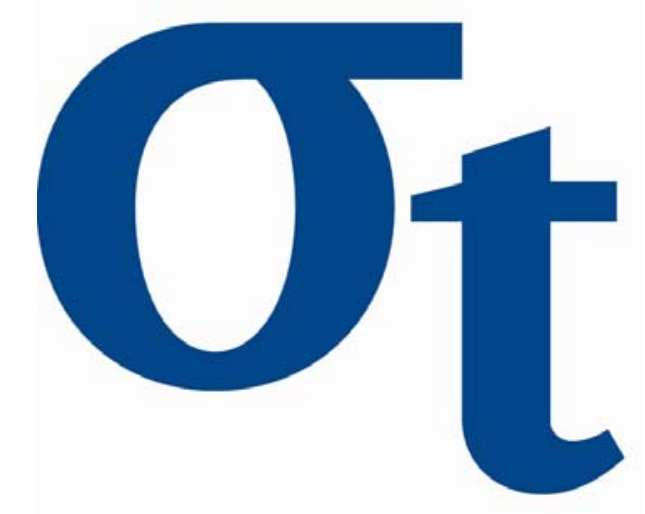

* Freie Universität Berlin, Germany

This research was supported by the Deutsche Forschungsgemeinschaft through the SFB 649 "Economic Risk". 


\title{
What Happened to the Transatlantic Capital Market Relations? ${ }^{1}$
}

\author{
Enzo Weber \\ Institut für Statistik und Ökonometrie, Freie Universität Berlin \\ Boltzmannstr. 20, 14195 Berlin, Germany \\ eweber@wiwiss.fu-berlin.de \\ phone: +49 30 838-55792 fax: +49 $30838-54142$
}

\begin{abstract}
This paper investigates the capital market relations between Euroland and the USA from 1990 until 2006. Formally based on the uncovered interest rate parity (UIP), backward recursive estimations establish a long-run equilibrium between European and US government bond yields. Since the mid-1990s though, cointegration can only be achieved additionally considering the exchange rate. The reason proves a stochastic trend common to the European interest and the exchange rate, consistently explained by central bank reactions and unfinished learning processes on the role of the euro. Furthermore, the US capital market dominance is strongly reduced, leading to transatlantic interdependence at eye level.
\end{abstract}

Keywords: Capital Market, UIP, Euro Area, United States

JEL classification: E44, F31, C32

\footnotetext{
${ }^{1}$ This research was supported by the Deutsche Forschungsgemeinschaft through the CRC 649 "Economic Risk". I am grateful to Jürgen Wolters, Cordelia Thielitz and Till Weber for their help. Of course, all remaining errors are my own.
} 


\section{Introduction}

In the year 1999 eleven member states of the European Union (EU) joined to create the euro, a common currency dedicated to foster economic growth and integration in its area. This step marks the final stage in the historic foundation process of the European Economic and Monetary Union (EMU). Nevertheless, the first years saw non-trivial currency depreciation, giving grounds to discussions about the stability of the euro and its strength in international comparison. Meanwhile, the situation has changed, and concerns in Europe are rather directed to export competitiveness.

In this context, one crucial question refers to the role of the euro area assets in international capital markets. On the one hand, the long-term interest rate, which is crucial for determining investment, is expected to react with respect to the domestic business cycle situation and monetary policy impulses. On the other hand, arbitrage between bonds denominated in different currencies, as stated by the uncovered interest rate parity (UIP), as well as exchange rate developments bring in foreign influences. The degree of internal autonomy a country can preserve apparently depends on its strength in international relations. This constellation makes capital market leadership to be a key factor for the interaction between financial sector and real economy.

Although the literature on international interest rate connections is well elaborated, analyses including EMU data remain relatively scarce. Up until now, for example Wolters (2002), Ehrmann and Fratzscher (2002, 2004), Chinn and Frankel (2003) as well as Brüggemann and Lütkepohl (2005) have considered interest rate relations between Europe and the US. As a main result, predominantly the European markets have been found depending on US influences, while reverse effects gained little significance. The present approach demonstrates an intriguing change in this pattern, which takes place since the mid-1990s and thus noticeably coincides with the third stage of EMU.

A furthermore important contribution of this paper lies in providing insight into the distinct role of the exchange rate in capital markets, since a remarkable development has taken place in the run-up to the euro introduction: While bivariate cointegration between the European and US bond yields confirms validity of the classical UIP theory until the early 1990s, thereafter a long-run equilibrium does not survive without including the euro/dollar exchange rate. The reason turns out to be a systematic reaction of the European interest rate to exchange rate fluctuations, introducing a second stochastic trend into the system. Subsequent economic argumentation suggests, that this phenomenon can be straightforwardly explained by monetary policy reactions of the European Central 
Bank (ECB) and unfinished learning processes in the foreign exchange market concerning the role of the new European currency.

In terms of empirical methodology, I mainly employ multivariate time series analysis based on the notion of cointegration. The central estimations are carried out in vector error correction models (VECMs), where formally, I follow the procedure proposed by Johansen (1995). This allows for testing UIP validity, establishing long-run relations and analysing the adjustment to equilibrium deviations, which reflects the "balance of power" in the transatlantic relations. Furthermore, in order to shed light on changes and development of these relations, I apply the econometric tools within a backward recursive calculation scheme.

The underlying paper is organised as follows: Section 2 introduces the theoretical concept of the UIP, supplemented by considerations on the role of the exchange rate. Subsequently, I describe the econometric methodology, mainly the test and estimation procedures. Section 4 presents the various empirical results of the VECM estimations. In the end, a summary displays all relevant generalised interpretation of the findings and concludes the paper.

\section{Economic Foundation}

The fundamental theory on international linkage between different bond yields is formalised in the UIP equation. The economic rationale of the UIP is the ex ante arbitrage condition between domestic and foreign capital markets: Interest differentials between assets with equal maturity measured in local currencies with otherwise similar characteristics must be offset by corresponding expectations on currency revaluation. This leads to the logarithmic UIP version

$$
i_{t, m}-i_{t, m}^{*}=\frac{12}{m}\left(E_{t} s_{t+m}-s_{t}\right)+\rho_{t, m}
$$

where $i_{t, m}$ and $i_{t, m}^{*}$ are the annualised domestic and foreign interest rates with $m$ month maturity, $s_{t}$ is the logarithm of the spot exchange rate (in terms of domestic currency units per foreign currency unit) and $E_{t}$ the conditional expectations operator. $\rho_{t, m}$ denotes the logarithm of a risk premium, reflecting risk aversion, differences in credit worthiness and such.

In line with the relevant literature, assume the exchange rate integrated of order one 
(I(1)), or more special a random walk. Then, under rational expectations, the first term on the right hand side of (1) should at least be stationary. In this case, I(0) risk premium presupposed, a valid linkage following the UIP relation depends on interest differentials to be stationary, too. Hence, provided that interest rates represent I(1) processes, domestic and foreign bond yields should be cointegrated with the vector $(1,-1)$. In conclusion, the exchange rate development should not exert any influence on the long-run cointegrating capital market equilibrium. While I will call this the "classical" UIP, empirical results from section 4.2 surprisingly reveal cointegration between interest and exchange rates. Therefore, in the following I explore two ${ }^{2}$ contrasting theoretical scenarios.

Firstly, such a mechanism could work through central bank acting, since a weakening currency for example might provoke contractionary monetary policy decisions (McCallum 1994). In such a case, the exchange rate would enter the central bank reaction function, either due to its very own importance, or indirectly through monetary policy relevant measures like imported inflation and output. As a simple example, consider the special form

$$
r_{t}=\lambda\left(s_{t}-s^{*}\right)+\tilde{r}_{t}
$$

with $\lambda>0$. Here, the reference rate $r_{t}$ is adjusted depending on the deviation of the exchange rate from its policy target $s^{*}$; any further relevant factors are included in $\tilde{r}_{t}$. Since the focus is not on exploring comprehensive policy rules, this simplistic form should be convenient for my purposes. Equation (2) clarifies, that the interest rate $r_{t}$ must contain a stochastic trend of strength $\lambda$ from the exchange rate $s_{t}$. Through the term structure, the policy rate impulses can be transmitted into the long-term capital market, where the relevant exchange rate information is continuously processed through market expectations. As Taylor (1999) argues, bond yields can react to exchange rate impulses even under a conventional Taylor-rule: Anticipation of output and inflation responses affects expectations of future short-term interest rates, which are averaged in long-term yields under the no arbitrage condition.

Secondly, a purely market-based explanation can be related to the basic UIP principle. In this scenario, learning processes on the strength and role of the euro are not yet finished. Let's take the example, that market participants attach a certain probability $\pi$ to the fact,

\footnotetext{
${ }^{2} \mathrm{~A}$ third one, purchasing power parity (PPP), connects the exchange rate to the relation of the price levels. While this might serve as an additional explanation, I will not follow this way due to clear failure of PPP; according estimation results are available on request.
} 
that the euro is a "weak" currency, and $1-\pi$, that it is "strong" (for a related example, see Lewis 1994). Then, with the respective superscripts, rational conditional expectation takes the form

$$
E_{t} s_{t+m}=\pi E_{t}^{\text {weak }} s_{t+m}+(1-\pi) E_{t}^{s t r o n g} s_{t+m} .
$$

For convenience, let $E_{t}^{\text {weak }} s_{t+m}=\lambda E_{t}^{\text {strong }} s_{t+m}$ with $\lambda>1$, since the exchange rate is defined as "euro per US dollar". Inserting this in (3), subtracting $s_{t}$ on both sides and rearranging leads to

$$
E_{t} s_{t+m}-s_{t}=\left(E_{t}^{\text {strong }} s_{t+m}-s_{t}\right)+\pi(\lambda-1) E_{t}^{\text {strong }} s_{t+m}
$$

Now assume, that in reality, the euro is a strong currency. Then, argumentation from above tells, that the first term on the right hand side, $E_{t}^{\text {strong }} s_{t+m}-s_{t}$, must be stationary. In turn, it follows necessarily, that the second term, $E_{t}^{\text {strong }} s_{t+m}$, contains a stochastic trend. This trend is included in the expected change of the exchange rate with weight $\pi(\lambda-1)>0$. As this term stands on the right hand side of UIP equation (1), ceteris paribus the stochastic trend appears as well in the interest differential on the left hand side. When learning proceeds, $\pi$ will approach zero (or $\lambda$ will approach one), in this leaving rational expectations of the conventional form.

From a different point of view, standard macroeconomic capital account theory states an adjustment of exchange rates to international interest differentials: Unusually high domestic bond yields for example trigger capital inflows, translating into demand for the home currency and consequently causing appreciation. Empirically, this theoretical relationship requires a significant adjustment of the exchange rate to deviations from the long-run interest rate equilibrium. The process continues, until fallen domestic yields, expectations of depreciation or induced changes in the trade account have re-equilibrated the balance of payments. Whereas this mechanism connects appreciation to positive interest differentials, it is negative ones in the UIP equation (1) and the sketched theories of central bank acting and learning. However, this constellation is not contradictory, since depending on the direction of causality, the respective effects may clearly be of opposite sign.

Concisely, causal effects might run from bond yields to the exchange rate and vice versa. The determination of the specific cointegrating properties, long-run adjustments and short-run dynamics has to be left to the econometric examination. 


\section{Methodological Proceeding}

The basic data generating process in the econometric procedure is the VAR with lag length $q+1$

$$
y_{t}=c^{*}+\sum_{i=1}^{q+1} A_{i}^{*} y_{t-i}+u_{t}
$$

where $y_{t}$ contains the $n$ endogenous variables, $A_{i}^{*}$ are $n \times n$ coefficient matrices, $u_{t}$ is an $n$-dimensional vector of white noise errors and $c^{*}$ denotes the constants.

Before proceeding, assume that a unit root process is an acceptable description of the interest and exchange rate behaviour. According to Johansen (1995), the commonness of $n-r$ stochastic trends is reflected by a reduced rank of $A^{*}(1)$, with $A^{*}(L)=I_{n}-$ $\sum_{i=1}^{q+1} A_{i}^{*} L^{i}$. Consequently, one can write $A^{*}(1)=-\alpha \beta^{\prime}$, where $\beta$ spans the space of the $r$ cointegrating vectors, and $\alpha$ contains the corresponding adjustment coefficients. Granger's representation theorem leads to the VECM

$$
\Delta y_{t}=\alpha\left(\beta^{\prime} y_{t-1}+c\right)+\sum_{i=1}^{q} A_{i} \Delta y_{t-i}+u_{t}
$$

with $A_{i}=-\sum_{j=i+1}^{q+1} A_{j}^{*}, i=1, \ldots, q$. This representation assumes the constant absorbed in the cointegrating relation, thus reflecting a stable risk premium.

The unit root behaviour of the time series is checked by ADF tests (see Dickey and Fuller 1979), including a constant as deterministic term. Here, as well as in all subsequent models, the lag length is set following the Akaike information criterion and Lagrange multiplier (LM) autocorrelation tests. Simulated critical values for the null hypothesis of non-stationarity are taken from MacKinnon (1996).

The likelihood ratio trace test statistic (Johansen 1994, 1995) for the null hypothesis of at most $r$ cointegrating relations is given by

$$
\Lambda(r)=-T \sum_{i=r+1}^{n} \log \left(1-\hat{\lambda}_{i}\right)
$$

where $n$ is the number of endogenous variables and $T$ the number of observations. $\hat{\lambda}_{i}$ denotes the i-th largest squared sample canonical correlation between $\Delta y_{t}$ and the respective cointegrating relation, both corrected for the influence of the remaining regressors. Since 
the trace test is known to be distorted in small samples, I implement a correction of the test statistic based on the response surface analysis in Cheung and Lai (1993). Critical values are provided by Osterwald-Lenum (1992).

As I aim at establishing stylised facts about the development of the European-US capital market relations, system estimations will be carried out backward recursively: Beginning in 1990:01, the starting point of the sample will move successively towards the present, whilst the end point 2006:12 remains fixed. These calculations result in graphs showing the movement of the respective estimated magnitudes through time. The recursions are stopped in 2002:01 in order to leave a minimum of 60 monthly observations for the last estimation.

\section{Empirical Evidence}

\subsection{Data}

The capital market rates are represented by 10-year constant maturity standard government bond yields: US Federal Government Securities (Federal Reserve) and Euro Benchmark Bonds (Eurostat), the latter as GDP-weighted EU-11 bonds. The graphs for the sample 1990:01 - 2006:12 are shown in Figure 1 together with the euro/dollar exchange rate (ECU before 1999). A close co-movement between the interest rates is evident at least since the late 1990s. The sample trend is slightly downward sloping, and the troughs and peaks relate to the business cycle course, for example in the economic boom at the turn of the millennium. The exchange rate graph clearly makes the quick depreciation and recovery of the euro visible. In principle, the euro has hardly gone through any stable period up until now. Interestingly, the devaluation in 1999/2000 coincides with an US bond yield exceeding the European one by about one percentage point. When the euro started to re-appreciate, the interest differential had vanished.

For the empirical analysis, the exchange rate is transformed to logarithm multiplied by 100, so that taking first differences generates continuously compounded monthly returns in percentage points. On the interest rates, already measured in percentage points and remaining rather low, no transformation is applied. Investigating the integration properties of the data, Table 1 provides the ADF test results for the interest and exchange rates. In none of the cases, the null hypothesis of non-stationarity can be rejected at the $10 \%$ level. As additionally, the first differences are clearly stationary, I assume all series 

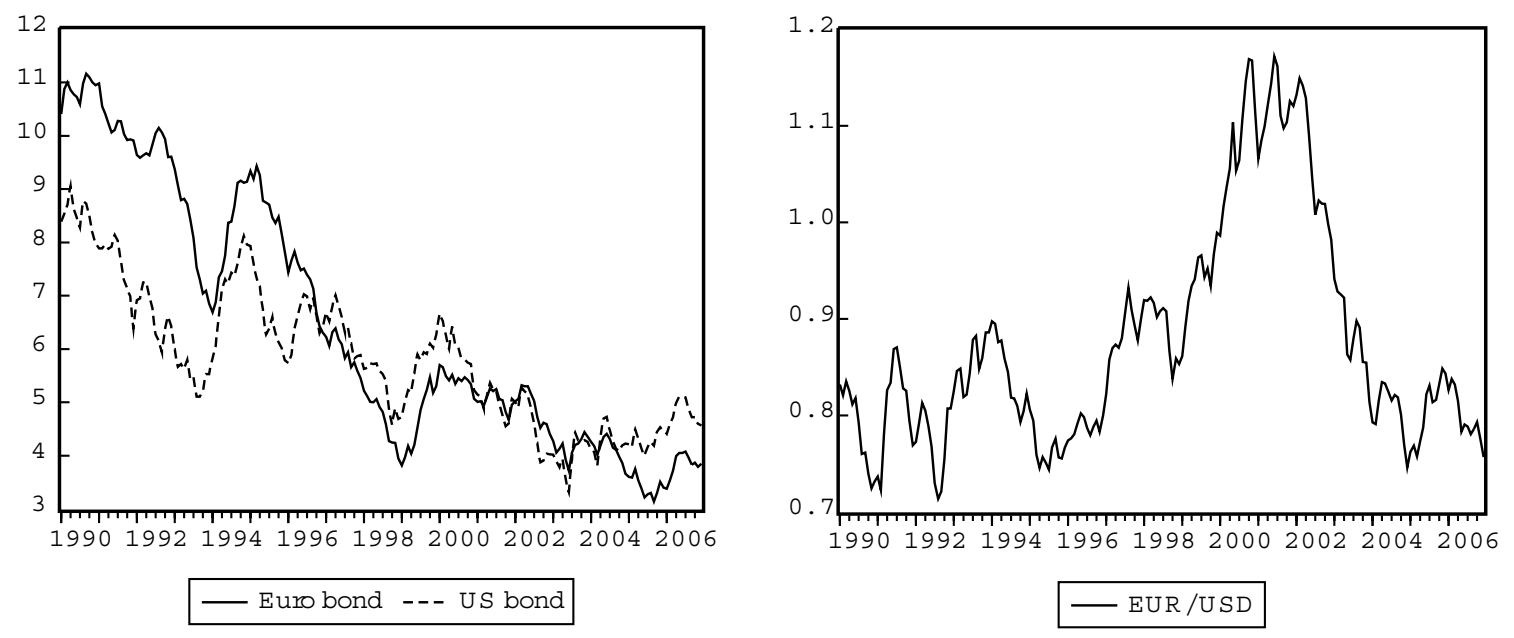

Figure 1: 10-year bond yields and exchange rate

integrated of order one.

\begin{tabular}{|l|c|c|c|}
\hline & Euro yield & US yield & EUR/USD \\
\hline p-value & 0.45 & 0.20 & 0.54 \\
\hline lag length & 2 & 1 & 2 \\
\hline \multicolumn{4}{|c|}{ Constant included } \\
\hline
\end{tabular}

Table 1: ADF tests (full sample)

\subsection{Evidence on Common Stochastic Trends}

This section serves to shed light on the cointegrating properties, and thus on the long-run equilibrium behaviour of the data. In this, classical UIP certainly requires bond yields to be driven by the same stochastic trend with equal weights. Consequently, the interest differential $i_{t}-i_{t}^{*}$ is tested for non-stationarity by backward recursive ADF tests. Since the constant proved clearly insignificant, no deterministic terms are included. This applies as well to the following models, and directs at the absence of permanent risk premia. The p-values in Figure 2 show, that until mid-1996 the null hypothesis of non-stationarity can be rejected on reasonable significance levels. Thereafter though, bivariate cointegration is not within reach anymore. This result does not depend on the implicit restriction $\beta=(1,-1)^{\prime}$, because neither an unrestricted trace test (available on request) is able to establish cointegration.

While for the first sample part one common stochastic trend could be established, a further trend is obviously present in the decade since 1996. Guided by the theoretical 


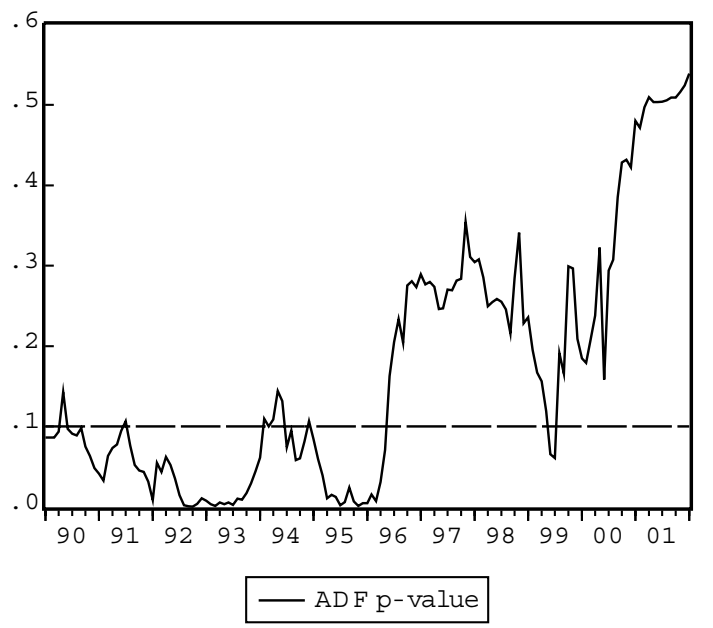

Figure 2: Backward recursive ADF tests on the Euro-US interest differential

reflections from section 2, I include the euro/dollar exchange rate together with the two bond yields as endogenous variables in a trivariate VECM. The Akaike criterion proposes a lag length of two, which remains a sensible choice in the subsequent estimations with recursive sample shortening. The system specification tests (LM for no autocorrelation, Jarque-Bera for normality, LM for no autoregressive conditional heteroscedasticity) in Table 2 show a satisfying model fit.

\begin{tabular}{|c|c|c|c|c|}
\hline & $\mathrm{LM}(1)$ & $\mathrm{LM}(12)$ & $\mathrm{JB}$ & $\mathrm{ARCH}(1) \mathrm{LM}$ \\
\hline p-value & 0.36 & 0.33 & 0.06 & 0.78 \\
\hline
\end{tabular}

Table 2: Specification tests (full sample VECM)

The trace tests in Figure 3 confirm, that including the exchange rate is indeed appropriate for constructing a stationary long-run relation: The null hypothesis of no cointegration can be rejected for the decisive second sample half, where the result necessarily depends on cointegration with the exchange rate. For the first years, stationarity of the interest differential (bivariate cointegration) has already been established, so that the exchange rate does not contribute to the cointegration here. Bearing in mind, that the additional eigenvalue in the trace statistic (7) therefore practically equals zero, the seeming lack of significance is only due to the higher critical value for three instead of two endogenous variables.

The fore standing explanations are substantially supported by the development of $\hat{\beta}_{3}$, the cointegrating coefficient of the exchange rate, in the trivariate VECM; together with a two standard error band, Figure 4 (right panel) tracks the backward recursive coefficients through the sample. Expectedly, significance cannot be reached in the period with valid 


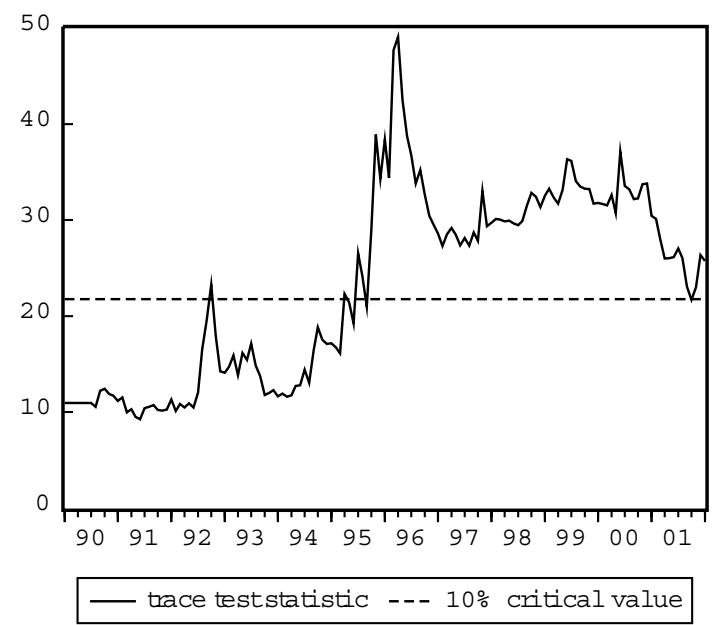

Figure 3: Backward recursive trace tests (Euro / US bond yields and exchange rate)

classical UIP, but later on, the exchange rate proves crucial for the stationarity of the long-run equilibrium. In turn, the US coefficient (left panel) does not deviate from the theoretically predicted -1 in the first sample part, but afterwards slightly falls below unity (in absolute value). In this, the European parameter is normalised to one.

While the equilibrium initially meets the classical UIP criterion $i_{t}=i_{t}^{*}$, it changes to about $i_{t}=0.96 i_{t}^{*}+0.03 s_{t}$ in the later period. Since the exchange rate had been defined as "euro per US dollar", a higher European interest rate goes hand in hand with a weaker European currency. This positive relationship is compatible with the theoretical considerations on central bank acting on the European side and unfinished learning, see equations (2) and (4), respectively. The following section provides profound support for this view.
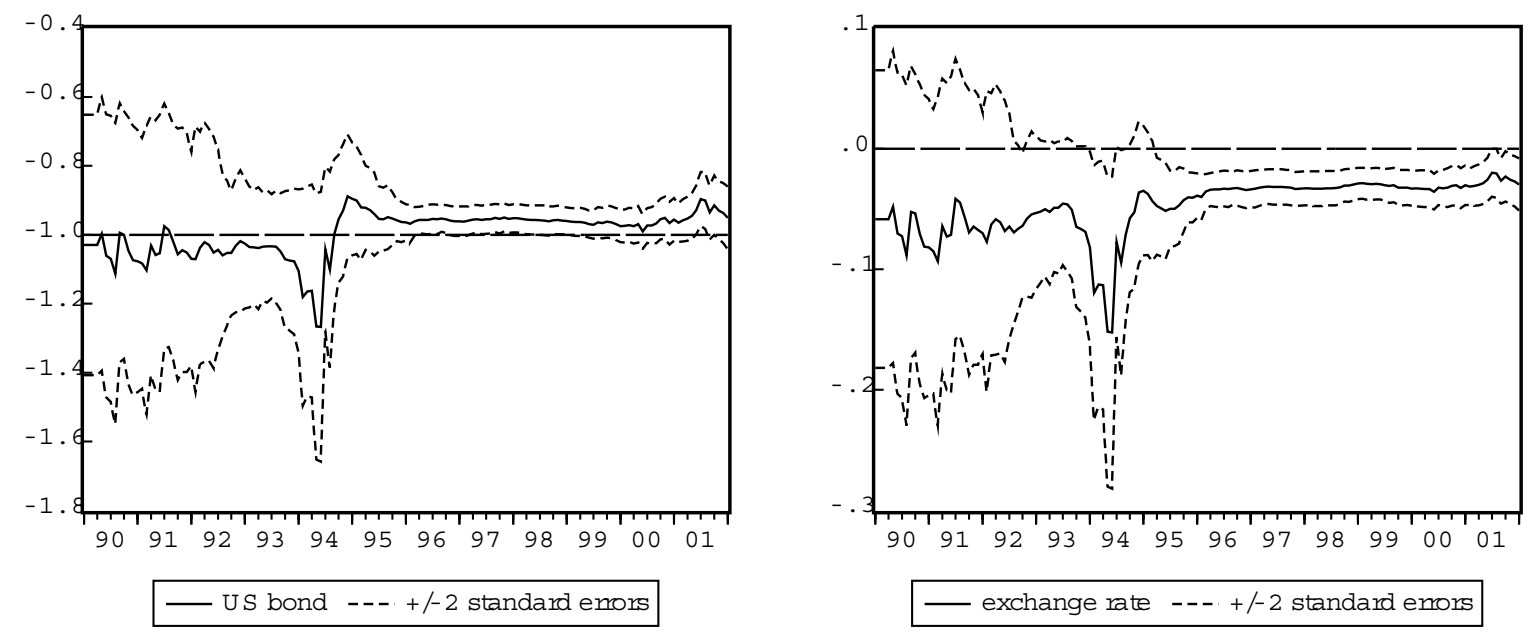

Figure 4: Backward recursive cointegrating parameters 


\subsection{Interaction of Capital and Foreign Exchange Market}

Having the cointegrating properties of the data explored, I now address the question of causal relationships between bond yields and exchange rate in the trivariate VECM. First, the backward recursive t-values of the respective $\alpha$ coefficients in Figure 5 give information on significance of adjustment to long-run equilibrium deviations. In the first sample part, it is obviously the European bond yield, which re-equilibrates the system and consequently keeps up the UIP condition. Over the years though, the European tstatistic moves towards the insignificant area, while its US counterpart at the same time approaches the upper critical value. Notwithstanding these developments, most striking may be the constant fall in the line representing the reaction of the exchange rate: In the period characterised by classical UIP, it is not affected by equilibrium deviations, anyhow afterwards, the adjustment is significantly negative. ${ }^{3}$ Recalling the "euro per US dollar" definition of the exchange rate, a European bond yield exceeding the US American one thus appreciates the euro, what is perfectly in line with intuition from capital account modelling.

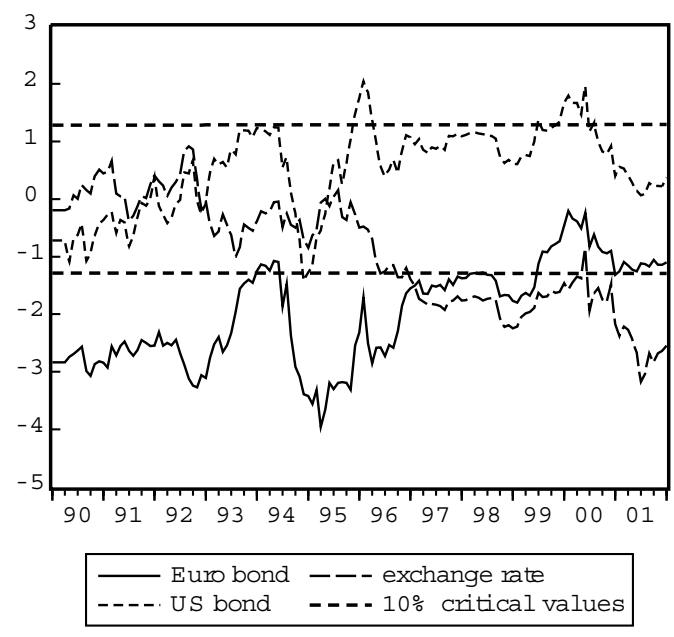

Figure 5: Backward recursive t-statistics of adjustment parameters

Figure 6 additionally underpins the last result: The graphs visualise the backward recursively estimated long-run impacts of unit shocks in the respective bond yields on the exchange rate. Since no sensible decision can be made on the identification of the contemporaneous impacts, the means of the respective values from all six possible Choleski decompositions are taken as the relevant measures; incidentally, this applies as well to the

\footnotetext{
${ }^{3}$ It is true, that the combination of a negative adjustment and cointegrating parameter belonging to the same variable tends to destabilise the system, but this is easily compensated for by the interest rates.
} 
forecast error variance decompositions below. Noteworthy effects cannot be established until 1996, but then, the US interest rate remarkably depreciates the euro, while the reverse is true for the European rate.

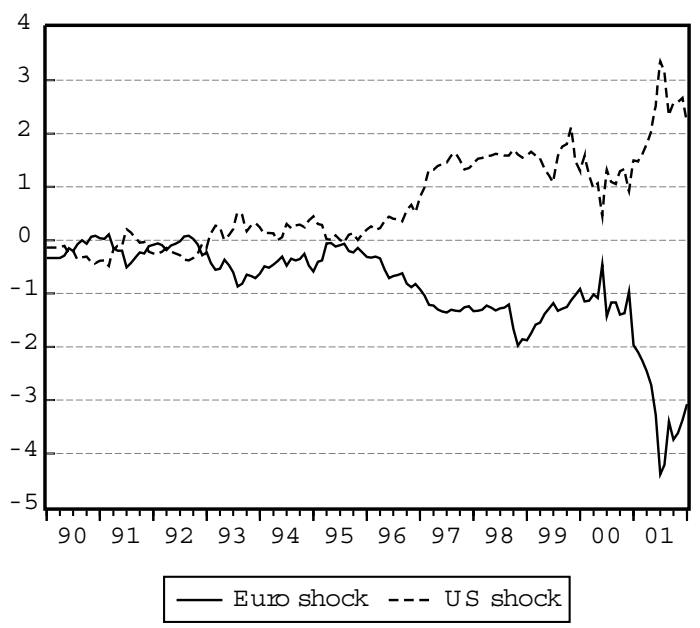

Figure 6: Backward recursive long-run effects of bond yield shocks on the exchange rate

The previous argumentation clarified, that the positive equilibrium relation between the interest differential and the exchange rate does not cast doubt on the common sense effects of capital flows. Necessarily, the outcome is caused by a positive influence in the reverse direction, namely from the exchange rate on the interest differential. As an illustration, Figure 7 presents the backward recursive contributions of exchange rate shocks to the long-run forecast error variances of both bond yields. These variance decompositions measure the overall degree of dependence of the respective interest rates on the exchange rate.

While the proportion in the US variance is largely negligible, in the second sample part about 40 percent of the European variation are governed by exchange rate innovations. Using a time window of about 60 months instead of the applied backward recursion with fixed endpoint even reveals almost no effect in the first sample years. ${ }^{4}$ Therefore it can be concluded, that since the mid-1990s there is a systematic positive reaction of the European interest rate to euro depreciation (and negative to appreciation).

Another simple experiment shall support the choice to link the stochastic exchange rate trend to the European bond yield: Figure 8 plots the backward recursive t-statistics of both interest rates in the OLS regression $s_{t}=c_{1}+c_{2} r_{t}+c_{3} r_{t}^{*}$. Taken the non-stationarity of the data into regard, the US bond yield remains entirely insignificant, whereas the

\footnotetext{
${ }^{4}$ According estimation results are available on request.
} 


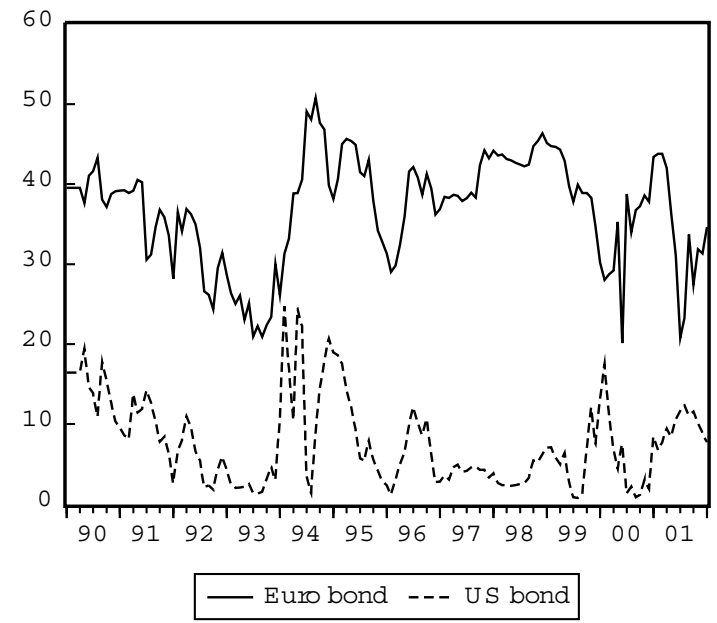

Figure 7: Backward recursive exchange rate contribution to long-run bond yield variances

European t-statistic reaches considerable values. Provided that a non-stationary component shared with the exchange rate does indeed exist, it can logically be attributed to the European bond yield.

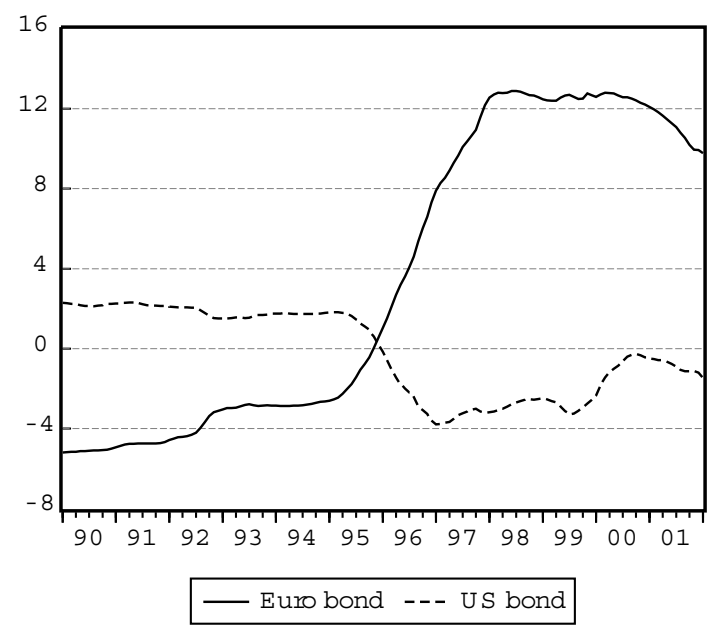

Figure 8: Backward recursive t-statistics (exchange rate regressed on bond yields)

Both explanations from the theoretical part 2, central bank acting and unfinished learning, are compatible with this constellation: Firstly, in connection with the formation of the European monetary union, public attention was directed to stability and credibility of the euro. Logically, the newly founded ECB was keen on supporting the strength of the new currency by an accordingly restrictive monetary policy. Namely, this means raising interest rates in case of inflation risks and depreciation, producing the positive relationship in (2). This argumentation gains additional significance in times of perceived currency misalignment, like the years directly following the euro introduction. For the period 
from 2002 until 2004, where the euro re-appreciated, the whole process could have worked straight into the opposite direction. Admittedly, since the ECB is not primarily dedicated to growth targets, interest rate lowering for example aiming at export competitiveness is not as likely as the contractionary scenario. Nonetheless, the returning of the euro towards more preferable rates was accompanied by an increased scope for monetary loosening.

Secondly, for obvious reasons it is likely, that markets underwent a learning process concerning the role of the euro. Experiences with the new situation were scarce, and despite the confidence into European economic stability, fears of landmark depreciation were widely spread. Even if nowadays the euro has stabilised, the scenario of a "weak" currency may have led to actual devaluation expectations as in (3), provoking classical self-fulfilment. Since additionally, the US exceeded the European interest rate, capital outflow and currency weakening were a logical consequence. Later on, when markets had gained experience, or had "learned" on the nature of the euro, and bond yields were realigned, appreciation could lead back towards the real "strong" exchange rate, which may have been reached in 2004. In spite of all evidence, this stylised argumentation does of course not claim knowledge about any profound equilibrium value of the euro.

\subsection{Capital Market Leadership}

At last, I proceed to the original question of leadership in the capital market, which has already been addressed in connection to the long-run adjustment coefficients (Figure 5). In detail, the task is to find out, to which extent changes in the bond yields are due to foreign capital market influences. For this purpose, Figure 9 displays the mutual backward recursive long-run variance contributions between the two bond yields. In the first years, the line representing the US influence exceeds the European one by far, but thereafter, a gradual fall in the former and a sudden rise in the latter balance both proportions at about 40 percent. Obviously, the expected US dominance has given way to an interdependence at eye level, at least since the mid-1990s.

Through time, the EMU has evidently adopted a stronger position in the international financial markets. Besides for the capital market, this has also important implications for the real economy: A complete dependence on foreign capital markets would imply, that the interest rate development could deviate uncontrollably from the needs of the domestic economy. In contrast, a certain degree of autonomy should allow the long-term interest rates to fill the important functions of dampening business cycles and determining investment. By the same token, the central bank should be able to conduct monetary 


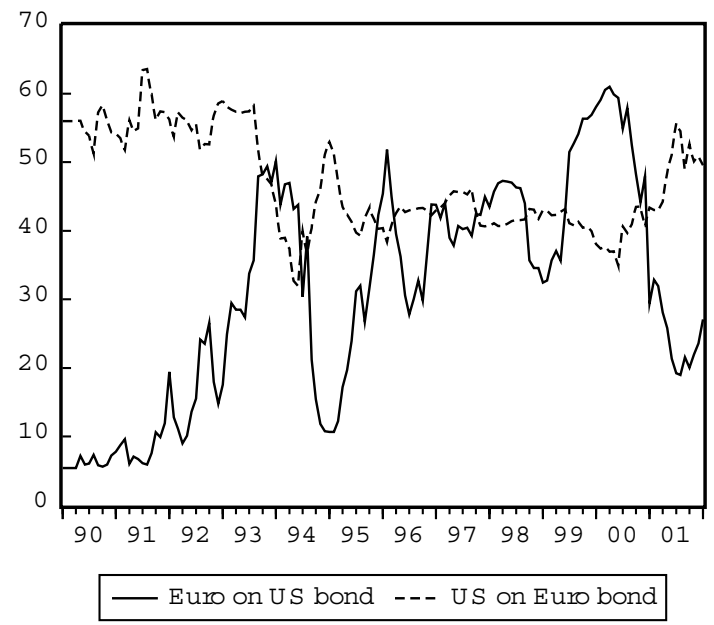

Figure 9: Mutual backward recursive contributions to long-run bond yield variances

policy orientated towards the domestic economic situation. While the strengthening of the influences radiating from the European capital market is beyond doubt, one should keep in mind, that the European bond yield is still substantially governed by exchange rate developments.

\subsection{Formally Testing Structural Breaks}

The previous backward recursive inference produced a clear pattern of systematic change in the behaviour of capital and foreign exchange markets. In order to provide additional statistical support for this finding, I conduct Chow sample-split tests (see Doornik and Hendry 1997), which basically check the null hypothesis, that full sample estimation is justified compared to splitting the sample into parts. While all coefficients are allowed to vary, the cointegrating vector $\beta$ is held constant, because reconsidering Figure 4, the main shift lies in the narrowing variances and not in the parameters themselves.

Figure 10 presents the p-values of the Chow tests with rolling break points. The null hypothesis of parameter constancy can evidently be rejected when splitting the sample in the mid-1990s, exactly where the substantial shifts in the various estimations have taken place. Therefore, the economic interpretations given in this paper can be convincingly supported. 


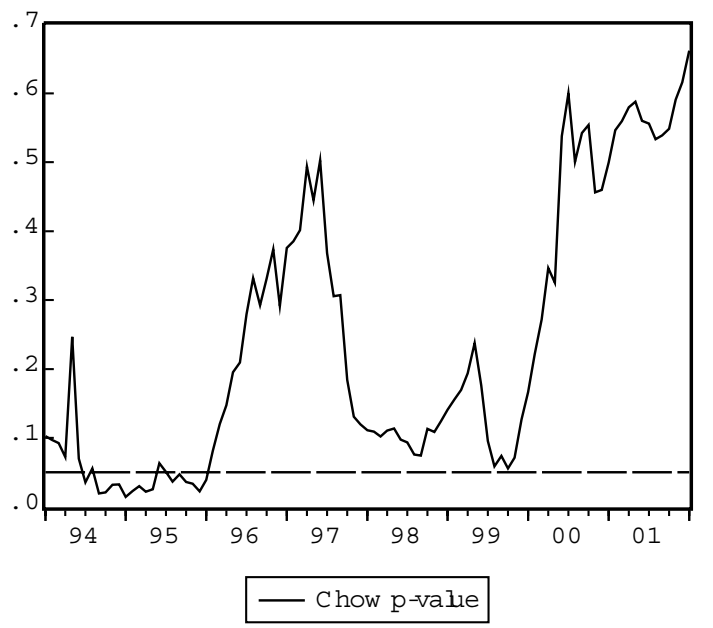

Figure 10: Chow sample-split tests for structural breaks at the respective time points

\section{Concluding Summary}

Starting out to shed light on the capital market connection between the euro area and the US, this paper naturally concentrates on the long-run UIP-based interest rate equilibrium. Backward recursive estimations at first can establish cointegration between the government bond yields, but since the mid-1990s, classical UIP does not prove valid anymore. A stable long-run relation can however be found when including the exchange rate in a trivariate VECM. This stands in contrast to conventional UIP theory, which rules out any level relation between interest and exchange rates. Furthermore, the positive long-run link between the European-US interest differential and the euro/dollar rate seemingly casts doubt on the economic sense of the empirical outcome.

Nevertheless, further econometric results favour the view, that besides the stochastic UIP trend, another non-stationary component is shared by the European bond yield and the exchange rate. Since the mid-1990s, a strong positive reaction of the European interest rate to exchange rate movements underlines this connection. Central bank behaviour aiming at stabilising the European currency comes as a straightforward explanation. Another plausible reason for the above-mentioned positive link stems from the learning of markets on the role of the new European currency. Anyhow, after all the reverse influence of the interest differential on the euro/dollar rate is still negative, what is in line with common sense theories.

Having the unusual role of the exchange rate explored, the study addresses the important question of economic leadership: At first, the US dominance fulfils the expectations, so 
that it is the European bond yield adjusting to re-equilibrate the capital market. After the early 1990s however, the feedback effects from the European side reach the same strength than the original US influence. Since no further exceptional exogenous events appeared in this period, it can be suggested, that the European unification with the completion of the monetary union has contributed to the change. In detail, it may have arisen from the lower sensitivity to foreign influences of the monetary union as a whole. For the same reason, the strategic position of one united European central bank has improved in comparison with the US, where since then, a single European interest rate could be observed by the markets. American weaknesses like the current account and budget deficits might have played an additional role.

For the European economy, the new situation means both exposure to the world markets as well as a certain scope for domestic policy, and therefore accordant responsibility as one of the world's strongest economic powers. Above all, the European monetary policy should be aware of this constellation. The US economy still holds on to the leading position, but this might be questioned by the European unification, of course in addition to the Asian economic miracle.

\section{References}

[1] Brüggemann, R., H. Lütkepohl (2005): Uncovered Interest Rate Parity and the Expectations Hypothesis of the Term Structure: Empirical Results for the U.S. and Europe. SFB 649 Economic Risk Berlin Discussion Paper 2005-035.

[2] Cheung, Y.W., K.S. Lai (1993): Finite sample size of Johansen's likelihood ratio tests for cointegration. Oxford Bulletin of Economics and Statistics, 55, 313-328.

[3] Chinn, M., J. Frankel (2003): The Euro Area and World Interest Rates. Santa Cruz Center for International Economics Working Paper 1016.

[4] Dickey, D.A., W.A. Fuller (1979): Distribution of the Estimators for Autoregressive Time Series with a Unit Root. Journal of the American Statistical Association, 74, 427-431.

[5] Doornik, J.A., D.F. Hendry (1997): Modelling Dynamic Systems Using PcFiml 9.0 for Windows. International Thomson Business Press, London.

[6] Ehrmann, M., M. Fratzscher (2002): Interdependence between the Euro Area and the US: What role for EMU? ECB Working Paper 200. 
[7] Ehrmann, M., M. Fratzscher (2004): Equal Size, Equal Role? Interest Rate Interdependence between the Euro Area and the United States. ECB Working Paper 342.

[8] Johansen, S. (1994): The role of the constant and linear terms in cointegration analysis of nonstationary time series. Econometric Reviews, 13, 205-231.

[9] Johansen, S. (1995): Likelihood-Based Inference in Cointegrated Vector Autoregressive Models. Oxford University Press, Oxford.

[10] Lewis, K.K. (1995): Puzzles in international financial markets. In: Grossman, G., K. Rogoff (eds.): Handbook of International Economics. North Holland, Amsterdam.

[11] MacKinnon, J.G. (1996): Numerical Distribution Functions for Unit Root and Cointegration Tests. Journal of Applied Econometrics, 11, 601-618.

[12] McCallum, B.T. (1994): A Reconsideration of the Uncovered Interest Parity Relationship. Journal of Monetary Economics, 33, 105-132.

[13] Osterwald-Lenum, M. (1992): A Note with Quantiles of the Asymptotic Distribution of the Maximum Likelihood Cointegration Rank Test Statistics. Oxford Bulletin of Economics and Statistics, 54, 461-472.

[14] Taylor, J.B. (1999): The Robustness and Efficiency of Monetary Policy Rules as Guidelines for Interest Rate Setting by the European Central Bank. Journal of Monetary Economics, 43, 655-79.

[15] Wolters, J. (2002): Uncovered Interest Rate Parity and the Expectations Hypothesis of the Term Structure: Empirical Results for the US and Europe. In: Klein, I., S. Mittnik (eds.): Contributions to Modern Econometrics, From Data Analysis to Economic Policy, Kluwer Academic Publishers, 271-282. 


\section{SFB 649 Discussion Paper Series 2007}

For a complete list of Discussion Papers published by the SFB 649, please visit http://sfb649.wiwi.hu-berlin.de.

001 "Trade Liberalisation, Process and Product Innovation, and Relative Skill Demand" by Sebastian Braun, January 2007.

002 "Robust Risk Management. Accounting for Nonstationarity and Heavy Tails" by Ying Chen and Vladimir Spokoiny, January 2007.

003 "Explaining Asset Prices with External Habits and Wage Rigidities in a DSGE Model." by Harald Uhlig, January 2007.

004 "Volatility and Causality in Asia Pacific Financial Markets" by Enzo Weber, January 2007.

005 "Quantile Sieve Estimates For Time Series" by Jürgen Franke, JeanPierre Stockis and Joseph Tadjuidje, February 2007.

006 "Real Origins of the Great Depression: Monopolistic Competition, Union Power, and the American Business Cycle in the 1920s" by Monique Ebell and Albrecht Ritschl, February 2007.

007 "Rules, Discretion or Reputation? Monetary Policies and the Efficiency of Financial Markets in Germany, 14th to 16th Centuries" by Oliver Volckart, February 2007.

008 "Sectoral Transformation, Turbulence, and Labour Market Dynamics in Germany" by Ronald Bachmann and Michael C. Burda, February 2007.

009 "Union Wage Compression in a Right-to-Manage Model" by Thorsten Vogel, February 2007.

010 "On $\sigma$-additive robust representation of convex risk measures for unbounded financial positions in the presence of uncertainty about the market model" by Volker Krätschmer, March 2007.

011 "Media Coverage and Macroeconomic Information Processing" by Alexandra Niessen, March 2007.

012 "Are Correlations Constant Over Time? Application of the CC-TRIG -test $^{-}$ to Return Series from Different Asset Classes." by Matthias Fischer, March 2007.

013 "Uncertain Paternity, Mating Market Failure, and the Institution of Marriage" by Dirk Bethmann and Michael Kvasnicka, March 2007.

014 "What Happened to the Transatlantic Capital Market Relations?" by Enzo Weber, March 2007.

SFB 649, Spandauer Straße 1, D-10178 Berlin

http:/ / sfb649.wiwi.hu-berlin.de 